Supplement of Hydrol. Earth Syst. Sci., 23, 2983-3005, 2019

https://doi.org/10.5194/hess-23-2983-2019-supplement

(c) Author(s) 2019. This work is distributed under

the Creative Commons Attribution 4.0 License.

(c) (1)

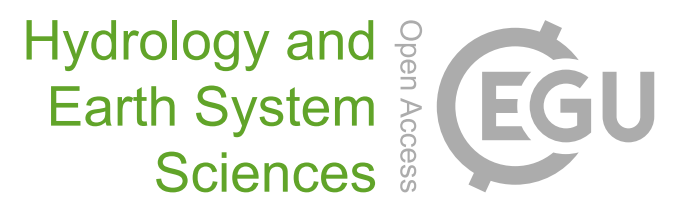

Supplement of

\title{
Monitoring snowpack outflow volumes and their isotopic composition to better understand streamflow generation during rain-on-snow events
}

Andrea Rücker et al.

Correspondence to: Andrea Rücker (andrea.ruecker@wsl.ch) and Jana von Freyberg (jana.vonfreyberg@usys.ethz.ch)

The copyright of individual parts of the supplement might differ from the CC BY 4.0 License. 


\section{Supplement}

- Figure S1: Measurements of hourly air temperature (a), daily precipitation (snow-and rainfall) and snow depth (b), and daily snowpack outflow volumes (c), measured at the mid-elevation forest (MF) site for the study period 1 November 2017 - 6 April 2018. Panel (d) shows daily discharge at the Erlenbach catchment outlet (on log scale). Vertical grey bars indicate the four rain-on-snow (ROS events 7-10) events during winter 2018 that are analysed only at the MF site (no measurements of snowpack outflow were available for the high-elevation, $\mathrm{HG}$, and mid-elevation, $\mathrm{MG}$, site).

- Table S1: Estimated contributions of rainfall or snowpack outflow to streamflow during peak flow based on two-component isotope hydrograph separation using $\delta^{18} \mathrm{O}$ (HG: high-elevation grassland site; MG: mid-elevation grassland site; MF: mid-elevation forest site).

- Table S2: Maximum contributions of rainwater or snowpack outflow to streamflow during daily discharge based on two-component isotope hydrograph separation using $\delta^{18} \mathrm{O}$ and $\delta^{2} \mathrm{H}$ (HG: highelevation grassland site; MG: mid-elevation grassland site; MF: mid-elevation forest site). The grey boxes with bold numbers indicate a different fraction compared to the fractions during peak flow (see Table 3 in the main text).

- Table S3: Relative contribution of rainwater to snowpack outflow during peak daily snowpack outflow based on two-component isotope hydrograph separation using $\delta^{18} \mathrm{O}$ or $\delta^{2} \mathrm{H}$ (HG: high-elevation grassland site; MG: mid-elevation grassland site; MF: mid-elevation forest site).

- Figure S2: Isotope hydrograph separations (IHS) using $\delta^{2} \mathrm{H}$ for the six ROS events during winter 2017, for "new water" end members comprised of snowpack outflow at the lysimeter sites HG (red), MG (yellow) and MF (green) as well as for rainwater sampled at the catchment outlet. The coloured bars indicate the rate of snowpack outflow or precipitation. The black lines indicate daily stream discharge, and the grey lines indicate the "new water" contribution from snowpack outflow or precipitation, as estimated by isotope hydrograph separation. 


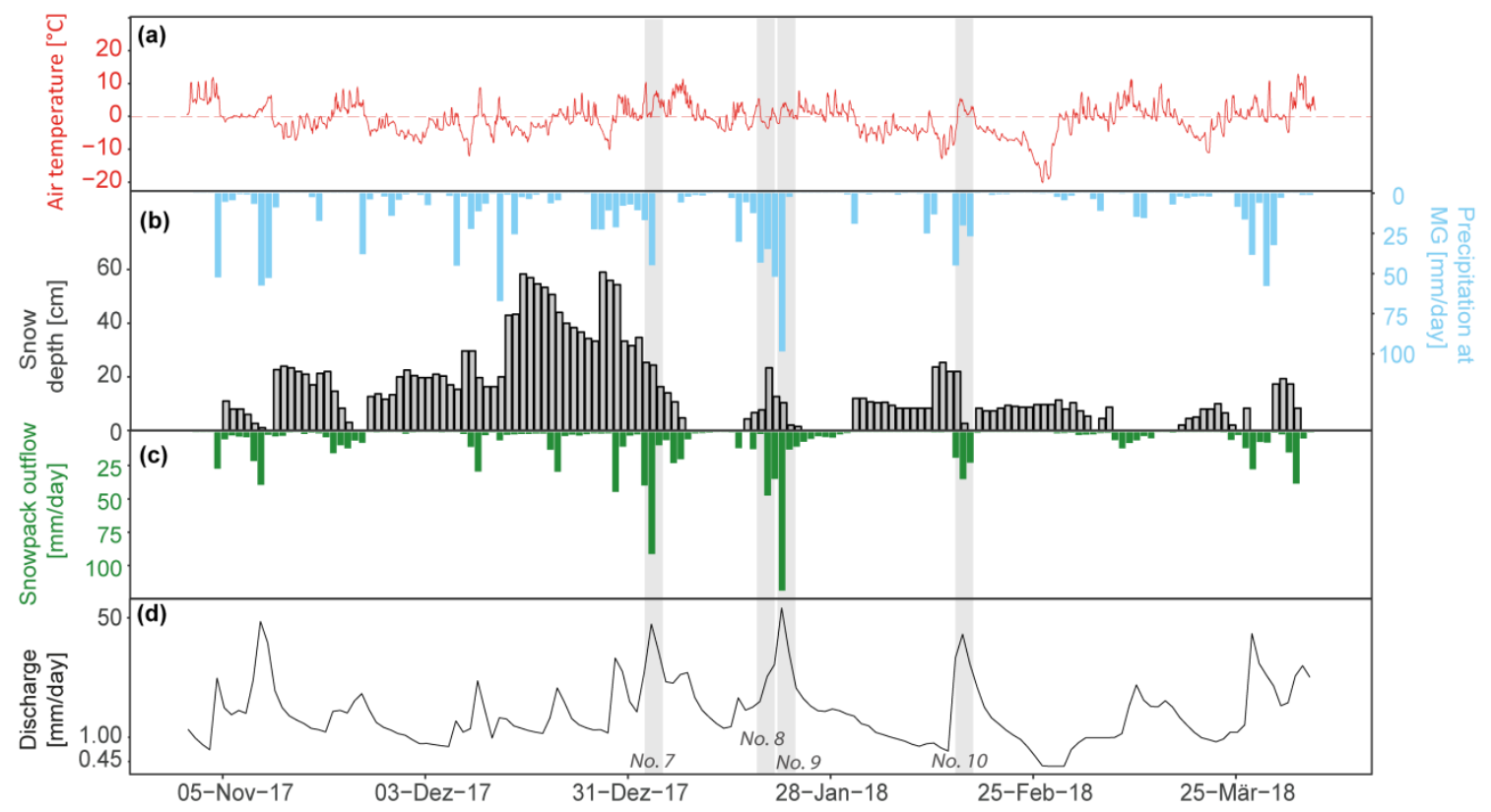

Figure S1: Measurements of hourly air temperature (a), daily precipitation (snow-and rainfall) and snow depth (b), and daily snowpack outflow volumes (c), measured at the mid-elevation forest (MF) site for the study period 1 November 2017 - 6 April 2018. Panel (d) shows daily discharge at the Erlenbach catchment outlet (on log scale). Vertical grey bars indicate the four rain-on-snow (ROS events 7-10) events during winter 2018 that are analysed only at the MF site (no measurements of snowpack outflow were available for the high-elevation, HG, and mid-elevation, MG, site).

Table S1: Estimated contributions of rainfall or snowpack outflow to streamflow during peak flow based on twocomponent isotope hydrograph separation using $\delta^{18} \mathrm{O}$ (HG: high-elevation grassland site; MG: mid-elevation grassland site; MF: mid-elevation forest site).

Relative contribution to peak daily discharge \pm SE $(\%)$

\begin{tabular}{ccccc}
$\begin{array}{c}\text { ROS event } \\
\text { number }\end{array}$ & $\begin{array}{c}\text { Snowpack } \\
\text { outflow HG }\end{array}$ & $\begin{array}{c}\text { Snowpack } \\
\text { outflow MG }\end{array}$ & $\begin{array}{c}\text { Snowpack } \\
\text { outflow MF }\end{array}$ & $\begin{array}{c}\text { Rainwater } \\
\text { (Outlet) }\end{array}$ \\
\hline No. 1 & a) & $117 \pm 21$ & $191 \pm 118$ & $68 \pm 11$ \\
No. 2 & $43 \pm 9$ & b) & $167 \pm 92$ & b) \\
No. 3 & $-19 \pm 15$ & $-59 \pm 61$ & $26 \pm 19$ & $11 \pm 8$ \\
No. 4 & a) & $30 \pm 12$ & $51 \pm 16$ & $205 \pm 947$ \\
No. 5 & $170 \pm 061$ & $41 \pm 9$ & $30 \pm 6$ & $2 \pm 4$ \\
No. 6 & $78 \pm 26$ & $12 \pm 5$ & $22 \pm 8$ & $9 \pm 4$ \\
\hline
\end{tabular}

${ }^{a)}$ no snowpack outflow occurred

b) data gap 
Table S2: Maximum contributions of rainwater or snowpack outflow to streamflow during daily discharge based on two-component isotope hydrograph separation using $\delta^{18} O$ and $\delta^{2} H$ (HG: high-elevation grassland site; MG: midelevation grassland site; MF: mid-elevation forest site). The grey boxes with bold numbers indicate a different fraction compared to the fractions during peak flow (see Table 3 in the main text).

\begin{tabular}{|c|c|c|c|c|c|c|c|c|}
\hline \multirow{3}{*}{$\begin{array}{c}\text { ROS } \\
\text { event } \\
\text { number }\end{array}$} & \multicolumn{8}{|c|}{ Maximum relative contribution to mean daily discharge \pm SE $(\%)$} \\
\hline & \multicolumn{2}{|c|}{ Snowpack outflow HG } & \multicolumn{2}{|c|}{ Snowpack outflow MG } & \multicolumn{2}{|c|}{ Snowpack outflow MF } & \multicolumn{2}{|c|}{ Rainwater (Outlet) } \\
\hline & $\delta^{18} \mathrm{O}$ & $\delta^{2} \mathrm{H}$ & $\delta^{18} \mathrm{O}$ & $\delta^{2} \mathrm{H}$ & $\delta^{18} \mathrm{O}$ & $\delta^{2} \mathrm{H}$ & $\delta^{18} \mathrm{O}$ & $\delta^{2} \mathrm{H}$ \\
\hline No. 1 & a) & a) & $117 \pm 21$ & $58 \pm 3$ & $191 \pm 118$ & $76 \pm 30$ & $68 \pm 11$ & $34 \pm 2$ \\
\hline No. 2 & $50 \pm 12$ & $50 \pm 3$ & b) & b) & $167 \pm 92$ & $91 \pm 20$ & b) & b) \\
\hline No. 3 & $9 \pm 9$ & $3 \pm 4$ & $12 \pm 9$ & $3 \pm 3$ & $26 \pm 19$ & $7 \pm 4$ & $11 \pm 8$ & $5 \pm 2$ \\
\hline No. 4 & a) & a) & $30 \pm 12$ & $29 \pm 4$ & $51 \pm 16$ & $46 \pm 6$ & $205 \pm 947$ & $22 \pm 1551$ \\
\hline No. 5 & $18 \pm 25$ & $263 \pm 64$ & $46 \pm 7$ & $64 \pm 7$ & $35 \pm 4$ & $42 \pm 1$ & $24 \pm 32$ & $32 \pm 1$ \\
\hline No. 6 & $78 \pm 26$ & $75 \pm 18$ & $33 \pm 84$ & $33 \pm 3978$ & $53 \pm 37$ & $45 \pm 1355$ & $23 \pm 104$ & $26 \pm 4$ \\
\hline
\end{tabular}

${ }^{\text {a) }}$ no snowpack outflow occurred

b) data gap

\section{Contribution of rainwater to snowpack outflow}

Isotope hydrograph separation at the scale of an individual snowpack can potentially quantify how much rainwater contributes to snowpack outflow during a ROS event, compared to pre-event water which was already stored in the snowpack (e.g., snowmelt). Such results can thus indicate how much rainwater was retained in the snowpack, especially when a snowpack was not yet saturated with pre-event liquid water. Unfortunately we could not perform these snowpack-scale hydrograph separations whenever the pre-event isotopic composition of snowpack outflow could not be obtained due to limited snowpack outflow generation prior to the event (event 1: HG, MG and MF; event 2: HG, event 6: MF was already snow-free) or during a data gap in the rainwater sampling (event 2). Thus, the results of this analysis should be used with caution.

In some cases, the estimated contributions of rain to snowpack outflow were unrealistic (e.g., negative contribution based on $\delta^{18} \mathrm{O}$ and/or $\delta^{2} \mathrm{H}$ ) because the isotopic composition of snowpack outflow did not respond to that of the incoming rainwater. These results indicate that rainwater infiltrated into the snowpack and pushed out pre-event liquid water, which thus made up most of the snowpack outflow with very little contribution from current rainfall (event 3: MG; event 4: MG, MF; event 5: HG). During event 5, the relative contribution of rainwater to snowpack outflow was heterogeneous among the three snowmelt lysimeter sites. At the MF site, the snowpack was already shallow (e.g., $8.6 \mathrm{~cm}$ ), so that rainwater contributed significantly to snowpack outflow $\left(74 \pm 3 \%\right.$ based on $\left.\delta^{2} \mathrm{H}\right)$ whereas the snowpack outflow at the HG site was less dominated by rainwater due to a deeper snowpack and higher contribution of pre-event liquid water $\left(16 \pm 2 \%\right.$ based on $\left.\delta^{2} \mathrm{H}\right)$. At the MG site, snowpack outflow was a mixture of both rainwater and pre-event liquid water $\left(49 \pm 3 \%\right.$ based on $\left.\delta^{2} \mathrm{H}\right)$.

During event 6 , the contribution of rainwater to the snowpack outflow at the MG site was high (e.g., $88 \pm 1 \%$ based on $\delta^{2} \mathrm{H}$ ) indicating that rainwater dominated the snowpack outflow. This result agrees with the observations in section 3.1.3, because this rainfall $(66.9 \mathrm{~mm})$ caused the melt-out of the ripe and shallow snowpack (e.g., $17 \mathrm{~cm}$ ), so that rainwater primarily contributed to the snowpack outflow. At the HG site, the measured snowpack outflow volumes indicated that the snowpack was not yet saturated (section 3.1.2), so that more rainwater was retained in the snowpack, pushing out pre-event liquid water and leading to a small contribution of rainwater to snowpack outflow $\left(24 \pm 8 \%\right.$ based on $\left.\delta^{2} \mathrm{H}\right)$. 
Table S3: Relative contribution of rainwater to snowpack outflow during peak daily snowpack outflow based on twocomponent isotope hydrograph separation using $\delta^{18} \mathrm{O}$ or $\delta^{2} \mathrm{H}$ (HG: high-elevation grassland site; MG: mid-elevation grassland site; MF: mid-elevation forest site).

\begin{tabular}{lcccccc}
\hline $\begin{array}{c}\text { ROS event } \\
\text { number }\end{array}$ & \multicolumn{5}{c}{ Relative contribution to peak daily snowpack outflow \pm SE (\%) } \\
& \multicolumn{2}{c}{ Snowpack outflow HG } & Snowpack outflow MG & Snowpack outflow MF \\
\cline { 2 - 7 } & $\delta^{18} \mathrm{O}$ & $\delta^{2} \mathrm{H}$ & $\delta^{18} \mathrm{O}$ & $\delta^{2} \mathrm{H}$ & $\delta^{18} \mathrm{O}$ & $\delta^{2} \mathrm{H}$ \\
\hline No. 1 & a) & a) & a) & a) & a) & a) \\
No. 2 & b) & b) & b) & b) & b) & b) \\
No. 3 & a) & a) & $-29 \pm 49^{\text {c) }}$ & $-10 \pm 22$ & $43 \pm 14$ & $57 \pm 15$ \\
No. 4 & a) & a) & $-197 \pm 195^{\text {c) }}$ & $-352 \pm 299^{\text {c) }}$ & $-158 \pm 51^{\text {c) }}$ & $-419 \pm 438^{\text {c) }}$ \\
No. 5 & $-8 \pm 3^{\text {c) }}$ & $16 \pm 2$ & $43 \pm 4$ & $49 \pm 3$ & $54 \pm 5$ & $74 \pm 3$ \\
No. 6 & $26 \pm 10$ & $24 \pm 8$ & $80 \pm 1$ & $88 \pm 1$ & snow-free & snow-free \\
\hline
\end{tabular}

a) no pre-event snowpack outflow occurred

b) data gap

c) unrealistic 


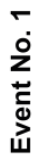
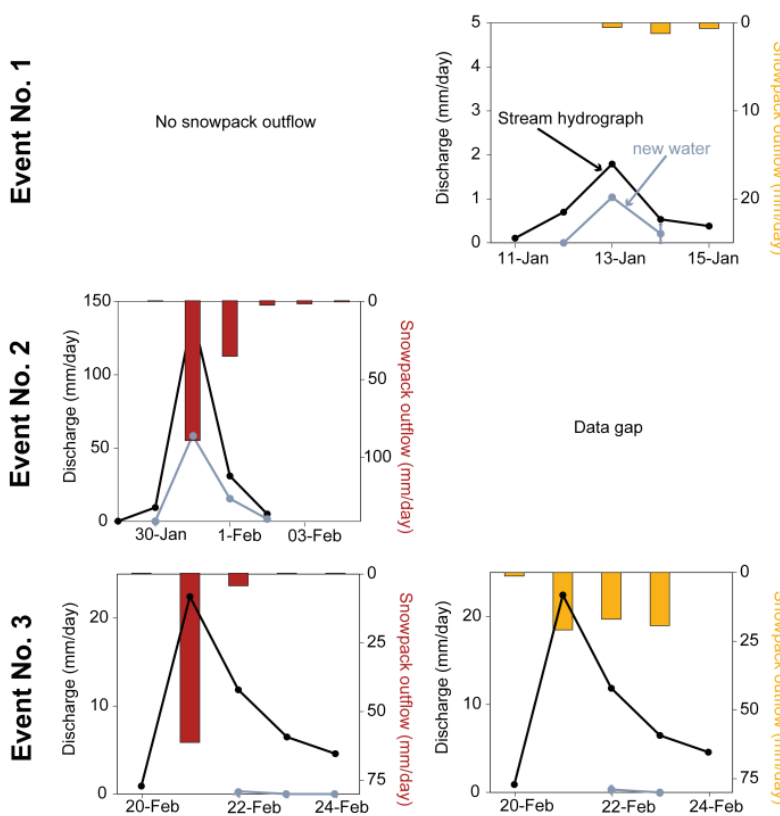

¿े
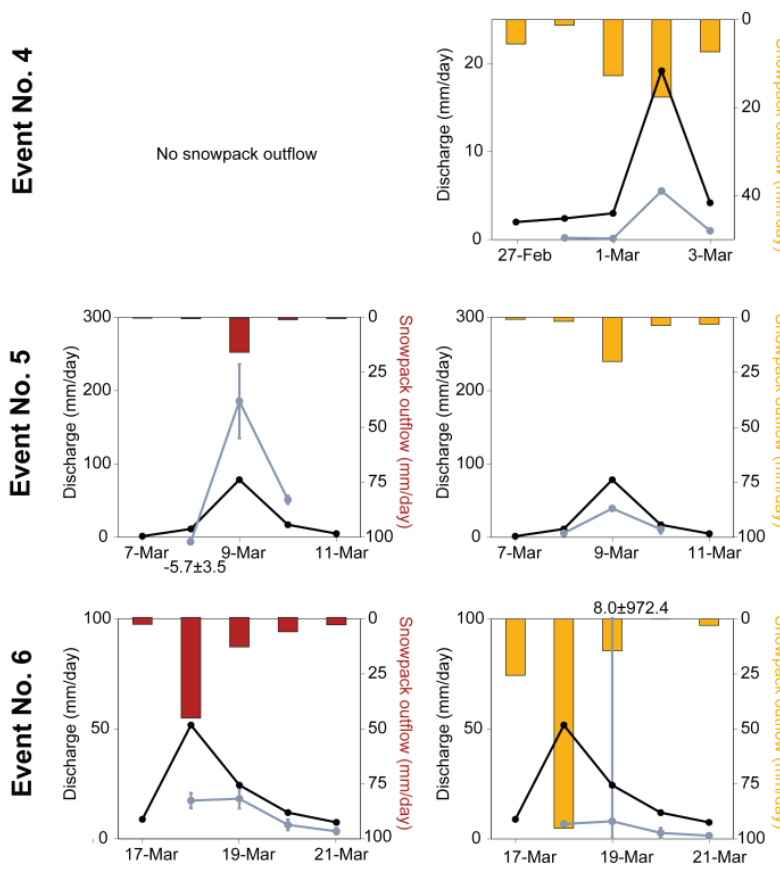
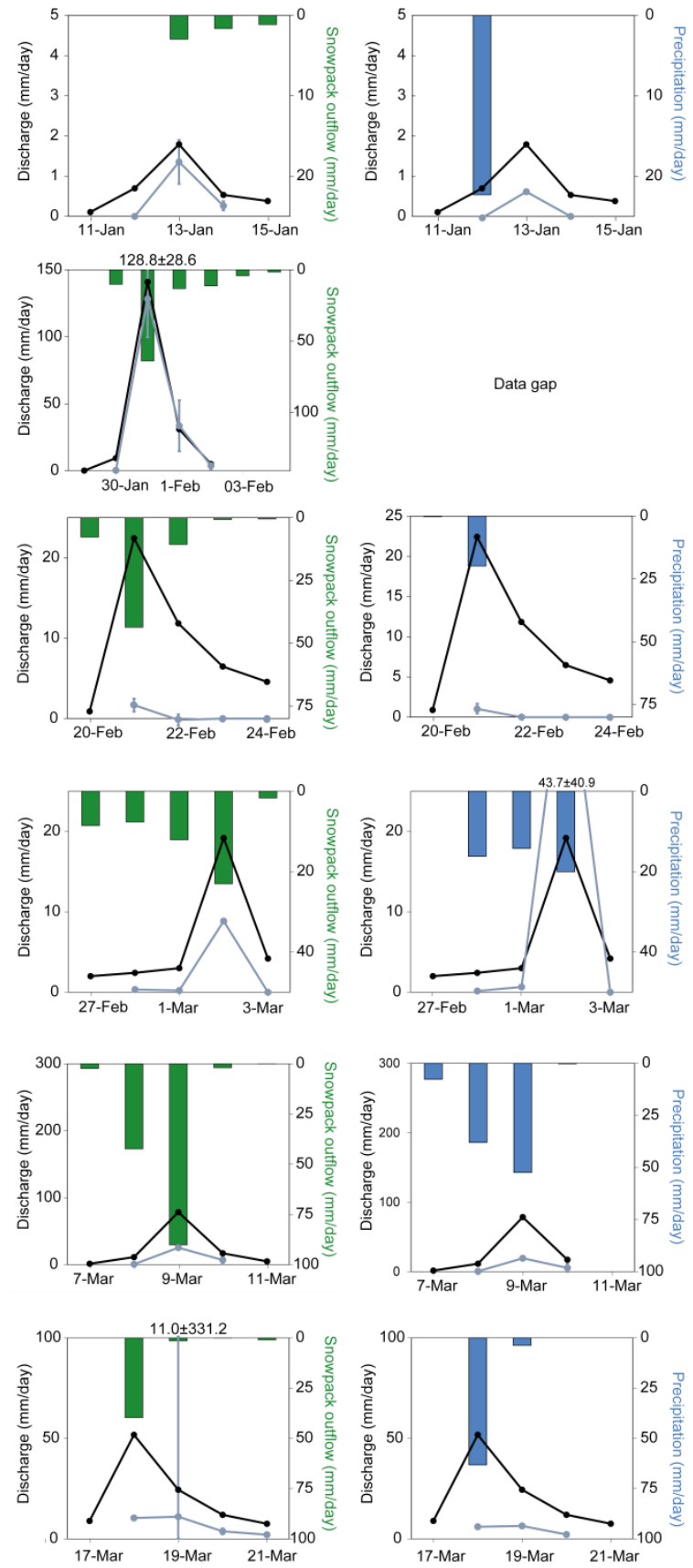

Figure S2: Isotope hydrograph separations (IHS) using $\delta^{2} H$ for the six ROS events during winter 2017, for "new water" end members comprised of snowpack outflow at the lysimeter sites HG (red), MG (yellow) and MF (green) as well as for rainwater sampled at the catchment outlet. The coloured bars indicate the rate of snowpack outflow or precipitation. The black lines indicate daily stream discharge, and the grey lines indicate the "new water" contribution from snowpack outflow or precipitation, as estimated by isotope hydrograph separation. 